\title{
Recent changes in the proportion of students identified with a disability, in Australian schools
}

\author{
Ian Dempsey \\ Centre for Special Education and Disability Studies, \\ University of Newcastle, Australia.
}

Running head: Recent changes in students with a disability

Address for correspondence:

Centre for Special Education and Disability Studies

University of Newcastle

Callaghan NSW 2308

Tel. 0249216282

Fax 0249216939

Email ian.dempsey@newcastle.edu.au 
This paper identifies and discusses recent increases in the percentage of students with a disability identified in Australian schools. At the moment, there is an unprecedented level of international debate about the nature of disability which is impacting on the identification of disability (see Donoghue, 2003; Greenspan \& Switzky, 2003). In association with this debate, Australia has seen several imperatives that have focussed attention on the identification of students with a disability in educational settings in the past decade.

The proportion of school students with a disability in Australian schools rose from 2.6\% in 1996, to 3.5\% in 2001 (Australian Productivity Commission, 1997, 2003). This increase in identification is demonstrated in Figure 1 which shows the proportion of Australian school students with a disability in 1996 and in 2001, by the state or territory of enrolment. The states and territories are arranged from left to right across this figure from largest to smallest population. There were increases in this proportion in five of the states and territories. The proportionate increase was most noticeable in the Northern Territory (with a high population of Aboriginal and Torres Strait Islander peoples).

There are a variety of reasons for this increased identification of disability, as well as reasons for the differences in rate of identification across the jurisdictions, which will be explored later. In addition, there are several factors that are likely to contribute to a continuing increase in the identification of disability in schools into the foreseeable future.

Figure 1 about here

The definition of disability used by the states and territories has been strongly influenced by the definition from the Department of Education, Training and Youth Affairs, and more recently by the States Grant (Primary and Secondary Education Assistance) Act (2000) (Department of the Parliamentary Library, 2000). This Act provides the framework for the provision of the majority of Commonwealth funding for school education, including funding for students with special needs. To be eligible for this funding, students must meet the definition under the Act. The Act defines a student with a disability as: 
- A student who attends a government or non-government school (whether or not as a distance education student) and in respect of whom a disability assessment has been made.

- A disability assessment means an assessment by a person with relevant qualifications, that the child has an intellectual impairment, a sensory impairment, a physical impairment, a social impairment, an emotional impairment or more than one of those impairments to a degree that satisfies the criteria for enrolment in special education programmes, provided by the Government of the State or Territory in which the student resides.

- Special education means education under special programmes, or special activities, designed specifically for children with disabilities and/or students with disabilities.

The proviso that a definition of disability relies, in part, on the eligibility of the student to receive special education services explains, to a large extent, the significant variations in identification of disability across the jurisdictions. Because it is tied to additional funding, the States Grant Act definition of disability has been criticised on a variety of counts. For example, the criticism extends to the distortion of schools' understanding of disability, the exclusion of some disability groups from the jurisdictions' operational definition of disability (e.g. learning disability, severe behaviour problems, language disorder), and the discretionary power given to the jurisdictions to decide who may be eligible to receive special education services, and as a consequence, who may have a disability. The lack of consistency in the definition of students with a disability in Australian schools is also causing difficulties in achieving the National Goals of Schooling for these students. However, there have been some recent initiatives that may assist in achieving improved consistency in definition.

A consequence of the passage of the Australian Disability Discrimination Act (DDA) (Department of the Parliamentary Library, 1992) in 1993 was an increased level of awareness, particularly in school communities, of the rights of students with a disability and their families. Evidence of this increased awareness can be found in changes to school enrolment policy (New South Wales [NSW] Department of Education and Training, 1997), the development of professional development 
resources (NSW Department of Education and Training, 1999; South Australian Department of Education, Training and Employment, 2000), and in legal precedent (Federal Court of Australia, 2000).

The DDA defines disability in very broad terms and it includes those students with special needs mentioned above who are not presently identified by schools as having a disability. While the DDA has increased awareness of disability in regular schools, which may account for at least some of the increase in the identification of disability, the Act has had a minimal impact on the definition of disability by schools, on enrolment patterns for students with a disability, and on regular classroom practice (Dempsey, 2003). However, this situation is likely to change following the ratification of education standards to supplement the legislation.

While the original DDA legislation addressed enrolment in educational institutions, it said nothing about the nature of educational services that should be provided in those institutions. The proposed education standards will address enrolment, participation in school activities, access to curriculum and support services, and harassment (Human Rights and Equal Opportunity Commission, 2003). At the time of writing, these education standards are likely to be passed into law by the Commonwealth in the near future. One consequence of the application of these standards in schools will be that the use of the Commonwealth's States Grant Act definition of disability by the states and territories, for general reporting purposes, will become redundant. Put simply, the legislative requirement to provide designated support to students with a disability will impel schools to identify students with a disability by using the relevant legislation (i.e. the DDA definition).

Some states and territories have responded to this imminent change with alarm. Their concern is fuelled by a perception that the incidence of disability will "blow out" as a consequence of the use of the DDA definition. In truth, the additional students that the jurisdictions are concerned about are, in almost all cases, already receiving some support from school literacy and numeracy programs, social skills training, and the like. 
In conclusion, the trend of an increase in the number of students with a disability identified in Australian schools is likely to continue in the short to medium-term as a consequence of the likely adoption of the DDA definition of disability by schools. Whether this "capture” of an additional group of students within the disability category leads to regular education reform, and the recognition by educators of a continuum of ability within Australian schools, remains to be seen. 
Figure 1. Percentage of all Australian school students with a disability, by state or territory, in 1996 and 2001.

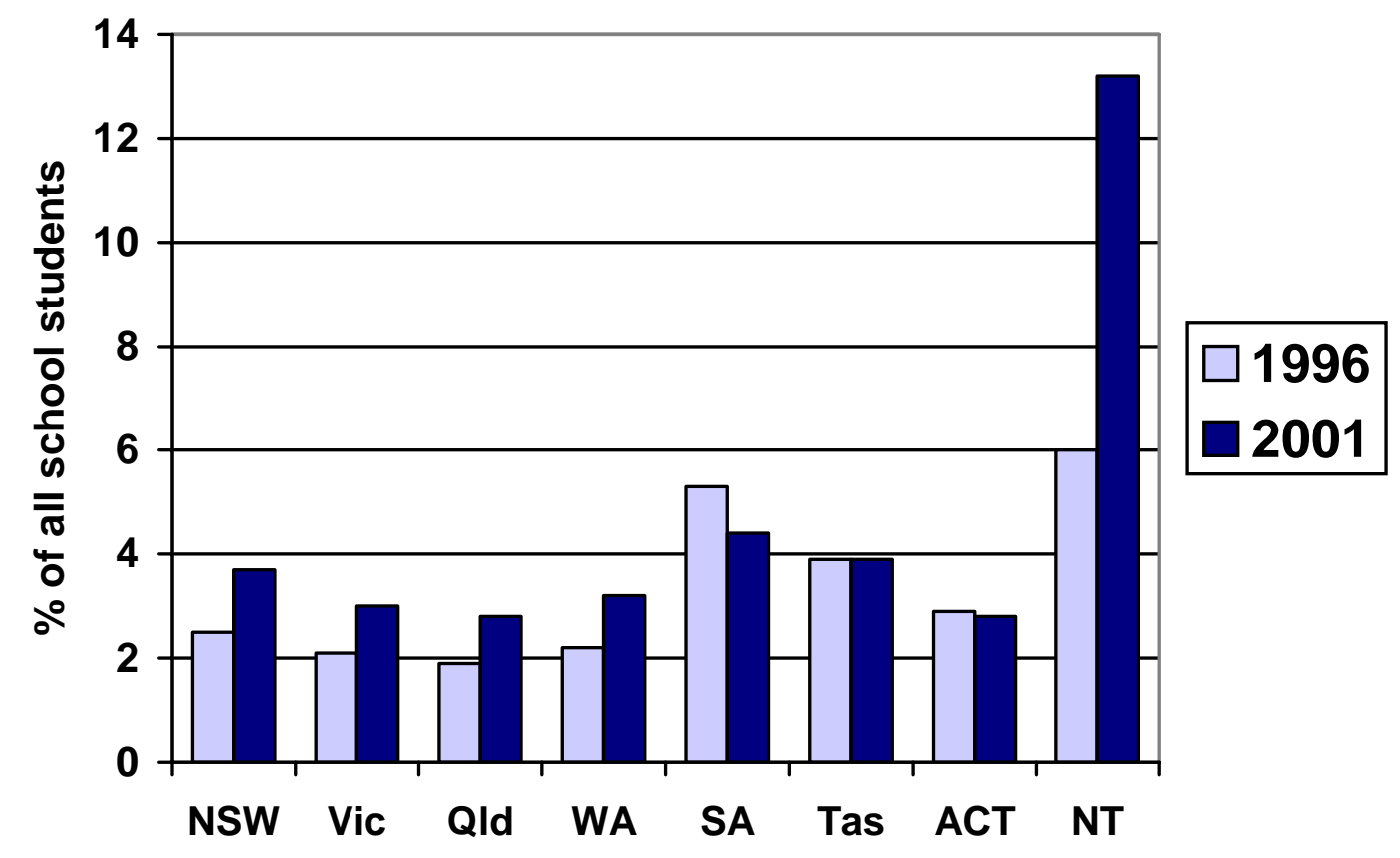

Data sourced from: Australian Productivity Commission (1998, 2003). 


\section{References}

Australian Productivity Commission (1998). Report on government services 1995. Retrieved from the World Wide Web on $18^{\text {th }}$ September, 2003. http://www.pc.gov.au/gsp/1998/index.html

Australian Productivity Commission (2003). Report on government services 2003. Retrieved from the World Wide Web on $18^{\text {th }}$ September, 2003. http://www.pc.gov.au/gsp/2003/index.html

Dempsey, I. (2003). The impact of the Disability Discrimination Act on school students with a disability in Australia. Australia and New Zealand Journal of Law and Education, 8, 1\&2, 35-44.

Department of the Parliamentary Library (1992). Disability Discrimination Bill 1992. Retrieved from the World Wide Web on December 22, 2003. http://parlinfoweb.aph.gov.au/piweb/view_document.aspx?ID=1371\&TABLE $=$ BILLSDGS

Department of the Parliamentary Library (2000). States Grants (Primary and Secondary Education Assistance) Bill 2000. Retrieved from the World Wide Web on December 22, 2003. http://www.aph.gov.au/library/pubs/bd/200001/01BD030.htm

Donoghue, C. (2003). Challenging the authority of the medical definition of disability: an analysis of the resistance to the social constructionist paradigm. Disability and Society, 18, 2, 199-208.

Federal Court of Australia (2000). Hills Grammar School v Human Rights \& Equal Opportunity Commission [2000] FCA 658. Retrieved from the World Wide Web on $23^{\text {rd }}$ September, 2003.

http://www.austlii.edu.au/au/cases/cth/federal_ct/2000/658.html

Greenspan, S. \& Switzky, H.N. (2003). Execution exemption should be based on actual vulnerability, not disability label. Ethics and Behaviour, 13, 1, 19-26.

Human Rights and Equal Opportunity Commission (2003). Disability Standards and Guidelines. Retrieved from the World Wide Web on 29 $9^{\text {th }}$ September, 2003. http://www.hreoc.gov.au/disability_rights/standards/standards.html\#employm ent

New South Wales Department of Education and Training (1997). Enrolment of students in NSW government schools: a summary and consolidation of policy. Retrieved from the World Wide Web on $23^{\text {rd }}$ September, 2003. http://www.det.nsw.edu.au/policies/enrolmen/enrostud/index.htm

New South Wales Department of Education and Training (1999). Students with disabilities in regular classes : learning together. Sydney: Author. 
South Australian Department of Education, Training and Employment (2000). Fair and reasonable : Disability Discrimination Act implementation kit. Adelaide: Author. 